\title{
Intercom e o futuro da pesquisa em Jornalismo
}

O professor Antônio

Hohlfeldt, que presidiu

a INTERCOM entre

2008 e 2014, avalia

as conquistas do con-

gresso para a área da

comunicação, discute os desafios que a pesquisa em jornalismo tem pela frente e retoma a importância da história para compreendermos a identidade da imprensa lusófona.

Por: Cândida Oliveira e Dairan Paul (doutoranda e mestre do POSJOR/UFSC). abertura do XVIII INTERCOM Sul, realizado em Caxias do Sul (RS), de 15 a 17 de junho, contou com a participação do professor Dr. Antônio Carlos Hohlfeldt, da Pontifícia Universidade Católica do Rio Grande do Sul (PUCRS), que, em sua fala, destacou sua trajetória na INTERCOM - Sociedade Brasileira de Estudos Interdisciplinares da Comunicação. Na entrevista a seguir, realizada por e-mail para a EJM, o jornalista e escritor retoma as conquistas da entidade, além de discutir o papel das pesquisas em Jornalismo em relação a novas tecnologias.

Hohlfeldt graduou-se em Letras pela Universidade Federal do Rio Grande do Sul (UFRGS), em 1973, com Mestrado (1991) e Doutorado (1998) na mesma área, ambos pela PUC-RS. Atualmente, é professor nos Programas de Pós-Graduação de Comunicação Social (FAMECOS) e Escrita Criativa (Faculdade de Letras).

Seus últimos estudos são desdobramentos do estágio pós-doutoral realizado na Universidade Fernando Pessoa, em 2008, quando pesquisou a história da imprensa lusófona através de jornais que circulavam nas antigas colônias portuguesas, de Angola e Moçambique a Cabo Verde e Goa. Um dos resultados a que chegou sugere traços em comum nas trajetórias destes países com o contexto de formação da imprensa brasileira.

$\mathrm{Na}$ entrevista a seguir, Hohlfeldt comenta sobre sua pesquisa atual que busca reconstituir uma história única sobre o jornalismo ibérico, dados os semelhantes processos de colonização nestes países. O professor também avalia a sua atuação como presidente da INTERCOM entre 2008 e 2014, período em que buscou "renovar e atualizar" a entidade, "sem perder relação com o passado". Durante sua gestão, Hohlfeldt estreitou as relações internacionais da INTERCOM com pesquisadores da África e ampliou a participação dos jovens pesquisadores nas atividades do congresso.

Quanto ao futuro da pesquisa em Jornalismo, o professor destaca a intensificação nos estudos em duas áreas, redes sociais e processos de democratização da informação. Hohlfeldt ainda sublinha o desafio que pesquisadores têm pela frente: estudar, entender, criticar, antecipar as conquistas tecnológicas e relatar os resultados de suas observações, a fim de compreenderem os usos da tecnologia e como melhor aproveitá-las democraticamente.

A seguir, confira a entrevista que Hohlfeldt concedeu para a EJM:

EJM - O senhor participou da conferência de abertura do XVIII INTERCOM Sul, com o tema "INTERCOM 40 anos: Memória, História e Comunicação". Em retros- 


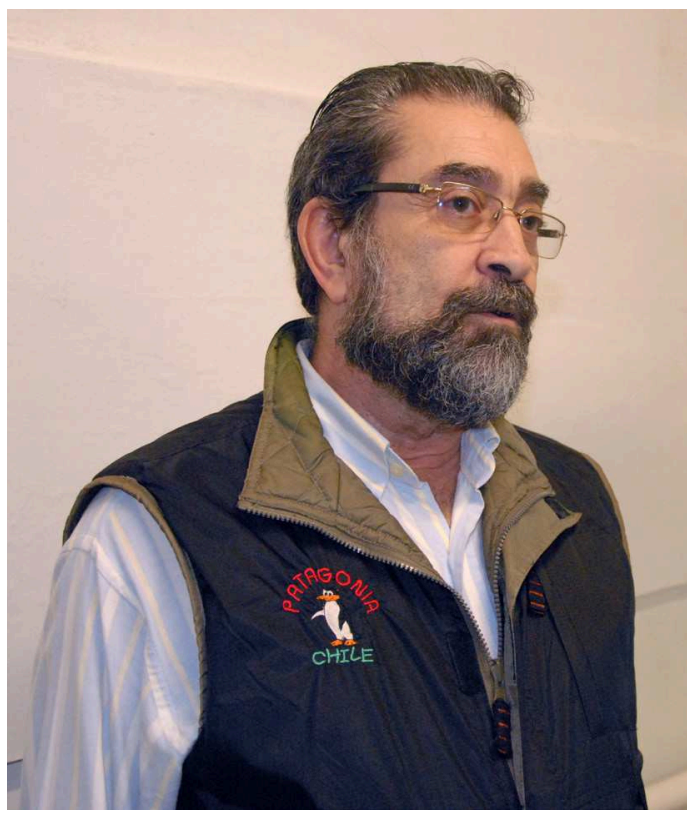

pecto, como avalia as conquistas para a área da comunicação e do jornalismo desde que o congresso e a entidade foram criados?

\section{ANTÔNIO HOHLFELDT - A INTER-} COM surgiu, enquanto entidade, após a criação da UCBC - União Cristã Brasileira de Comunicação -, de que uma parte significativa de pesquisadores brasileiros de comunicação se encontravam afiliados, inclusive eu. Estávamos em plena ditadura, e algumas igrejas, como a Católica, a Luterana e a Metodista, todas cristãs, apoiaram o projeto de criação desta entidade. A UCBC promoveu encontros históricos. Mas, bem ou mal, achava-se vinculada a um segmento religioso, de onde surgiu a inspiração para a criação da INTERCOM, absolutamente laica, embora constituída, em parte, pelos mesmos pesquisadores que formavam a UCBC. Desde logo, a INTERCOM reivindicou autonomia em relação inclusive ao governo de então. Enfrentou pressões, sobretudo quando da realização de seus primeiros congressos, mas também recebeu apoio incondicional dos pesquisadores brasileiros de comunicação. A experiência pretérita do prof. Dr. José Marques de Melo, primeiro tendo trabalhado junto a Luiz Beltrão, na Universidade Católica de Pernambuco, onde foi criado o primeiro curso de jornalismo, a primeira instituição de pesquisa - o ICINFORM - e a primeira revista acadêmica especializada permitiu que políticas importantes e consequentes fossem esboçadas. A formação de grupos de pesquisa, a abertura de espaço aos jovens acadêmicos de graduação, o vivo diálogo com pesquisadores estrangeiros - em especial, Estados Unidos, França, e depois Portugal, Espanha e países da América Latina - levaram à criação de outras entidades, formuladas a partir do modelo da INTERCOM, como a ALAIC e a SOPCOM. Um dado importante é que sempre com absoluto respeito pela autonomia de cada instituição.

Há alguns anos, a profa. Maria Cristina Gobbi e eu resolvemos editar um livro reunindo entrevistas e textos dos professores agraciados com o Prêmio Luiz Beltrão durante os primeiros 15 anos da entidade. Foi surpreendente o resultado: verificamos que todos os agraciados, naquele momento em que foram destacados, participavam ativamente de atividades acadêmicas e democratizantes - reitero, estávamos ainda na ditadura -, evidenciando que ser professor e pesquisador não significa se alienar em relação a outros contextos. Mais que isso, os textos apresentados por estes mesmos professores evidenciavam os grandes debates da área. Por exemplo: o ensino da comunicação, as então novas questões sobre tecnologias de informação e comunicação, etc. Ou seja, fica evidente, lendo-se os premiados, que a INTERCOM acompanhava, passo a passo, o que acontecia, surgia e se tornava polêmica no campo da comunicação, em nosso país.

Outra iniciativa fundamental para estabelecer diálogos produtivos foi a realização de simpósios internacionais. Hoje em dia, certamente muitos dos pesquisadores que mantém relações de pesquisa com colegas de outros países começaram tais relações justamente através destes simpósios. Por fim, não só a criação da revista INTERCOM, inicialmente semestral, como também a publicação de boletins que registravam o movimento bibliográfico do país, no campo da comunicação, a edição de livros e a realização de mesas temáticas no âmbito dos congressos, abriram horizontes largos para a mais ampla compreensão 
e acompanhamento do que se fazia, em termos de estudo sobre a comunicação, no Brasil e em boa parte dos principais centros acadêmicos mundiais. Destacase, enfim, que os espaços abertos para os jovens acadêmicos de graduação foi outra sábia decisão, porque abriu espaço para uma contínua renovação dos quadros da entidade, assim como um produtivo diálogo entre gerações diferentes.

EJM - Tratando especificamente de sua atuação na INTERCOM, que balanço o senhor faz dos seus dois mandatos?

ANTÔNIO HOHLFELDT - Um Presidente não trabalha sozinho. Nas duas gestões que liderei, na verdade, tive um conjunto de colegas pesquisadores excepcional. Tanto que a profa. Marialva Barbosa, que já vinha da gestão anterior do prof. José Marques de Melo, seria, depois, a Presidente da Intercom. E, nesse momento, o então tesoureiro, prof. Fernando Almeida, é, hoje, candidato na nova chapa, a ser formalmente eleita neste primeiro semestre de 2017, enquanto vice-presidente da chapa única que se apresentou ao processo eleitoral que culminará na posse da nova diretoria, em setembro vindouro.

O que tivemos de principal preocupação, seguindo estritamente os estatutos da entidade, foi escolher cada integrante da diretoria com capacidade para desempenhar as funções específicas que lhe cabiam naquela estrutura, além de formarem o grupo administrativo da entidade. Nossa marca foi, fundamentalmente, renovar e atualizar, sem perder a relação com o passado. Ou seja, fortalecemos o institucional da entidade, ao mesmo tempo em que buscamos adotar procedimentos contemporâneos, condizentes com as possibilidades das novas tecnologias. Ampliamos sobremaneira os espaços regionais - o Brasil é grande demais para centralizar tudo - e, ao mesmo temo, buscamos facilitar e viabilizar, institucionalmente, a participação das diversas regiões nos congressos do primeiro semestre, que culminam no grande congresso nacional de setembro.
Buscamos modernizar procedimentos e rotinas, fixando tudo em documentos, de modo que as próximas diretorias não tivessem que descobrir ou reaprender (ou adivinhar). Ficava tudo registrado, era só seguir aquele roteiro ou modificá -lo, atualizando-o, se fosse o caso.

Também nos ocupamos muito da revisão do portal institucional, ao mesmo tempo em que objetivamos nossas relações internacionais, exigindo o respeito e a equanimidade, de sorte que não apenas convidamos pesquisadores quanto instamos a que nossos pesquisadores fossem convidados para participar de outras atividades internacionais. Concretizamos a aproximação com a África, em especial com pesquisadores dos países de expressão portuguesa, como Moçambique, que hoje já tem sua associação, e Cabo Verde, que realizou já dois congressos inclusive. $\mathrm{Na}$ verdade, não se inovou grandemente, mas se deu maior dinamicidade e se buscou concretizar utopias e palavras de ordem já existentes, mas que, por um ou outro motivo, não haviam sido, ainda, alcançadas. Por fim, e muito especialmente graças à profa. Dra. Nelia del Bianco, então na UnB, criamos as regras e alocamos tecnologias que facilitasse e ampliassem a participação dos jovens nas atividades da INTERCOM.

EJM - Como se deu o processo de internacionalização da INTERCOM e, consequentemente, de suas pesquisas?

ANTÔNIO HOHLFELDT - O prof. Marques de Melo, a partir do prof. Luiz Beltrão, tinha alguns contatos iniciais a partir do CIESPAL - Centro Internacional de Estudios Superiores de Comunicación para América Latina, no Equador. Lá, também surgiram contatos com pesquisadores norte-americanos e franceses, que atuavam naquela instituição. Por outro lado, quando o prof. Marques de Melo foi afastado da USP, pelo golpe de 1964, acabou tendo a oportunidade de estudar nos Estados Unidos, o que ampliou ainda mais as relações com pesquisadores daquele país. E a partir do mesmo CIESPAL, estabeleceram-se as 
relações com pesquisadores latino-americanos. Por isso, desde logo, a INTERCOM se internacionalizou. A proximidade com Portugal e Espanha foram passos naturais, pela afinidade linguística, e a influência recíproca é tão forte que criaram-se, sucessivamente, a IBERCOM e outras entidades reunindo estes pesquisadores, promovendo encontros anuais ou bianuais, e assim por diante. Esta institucionalização de relações entre pesquisadores tem aberto caminhos importantes para pesquisas conjuntas, troca de estudantes pesquisadores e, evidentemente, articulações que se dão em âmbito de outras entidades, como a IAMCR - International Association For Media and Communication Research ou a ICA - International Communication Association, por exemplo.

EJM - Através da INTERCOM Júnior, o congresso estimula a formação de jovens pesquisadores desde a iniciação científica. Como estas políticas foram institucionalizadas na história do congresso e que avaliação o senhor faz dos resultados obtidos a partir delas?

ANTÔNIO HOHLFELDT - Estas institucionalizações, evidentemente, se dão com o tempo. E, hoje em dia, adaptando-se às características dos jovens pesquisadores, precisam encontrar suportes tecnológicos suficientes. Foi o que enfrentamos durante a primeira gestão que desenvolvi. Precisamos ampliar as possibilidades de envio de pesquisas e trabalhos que os jovens estudantes realizavam em suas unidades acadêmicas. $\mathrm{O}$ prof. Marques de Melo já havia iniciado este processo, e na minha gestão procurou-se dar amplitude a isso. $\mathrm{O}$ resultado é que, nos congressos regionais, temos hoje maioria de estudantes de graduação participando, e no congresso nacional, é quase meio a meio, no que toca às inscrições. Isso tem sido importante inclusive para o sustentáculo financeiro da instituição, mas o principal é que preparamos novas gerações de pesquisadores que vão nos suceder, assim como eu tive a oportunidade de me aproximar da entidade quando estudante de graduação. Neste sentido, é sempre exemplar e inolvidável - uso bem conscientemente estes dois termos - a atividade desenvolvida pelo prof. Marques de Melo, atraindo os jovens e abrindo espaços para a sua participação, comportamento que, para mim, é sempre modelo pra o que se deve fazer nas entidades que reúnem nossos pesquisadores.

EJM - Há políticas para a participação de pesquisadores mais jovens no quadro de gestores da INTERCOM?

ANTÔNIO HOHLFELDT - Sim, toda a diretoria é formada, evidentemente, por pesquisadores que já têm uma larga atividade na INTERCOM: participação de GTs com apresentação de trabalhos, coordenação de GTs e congressos regionais; é como uma espécie de ascensão permanente. Mas sempre temos, ao lado do pesquisador mais experiente, um jovem pesquisador que notamos destacarse nas atividades dos congressos. Assim, há uma circularidade permanente dos quadros sociais, o que garante a sobrevivência e a oxigenação da instituição, tanto quanto aquilo a que denominamos de capilaridade, isto é, a vinculação da entidade junto às bases, que são os pesquisadores de comunicação, os cursos de comunicação etc.

EJM - Como o senhor avalia a integração de pesquisas nacionais através dos Grupos de Trabalho da INTERCOM? Enquanto área inscrita na esfera da Comunicação, qual é o espaço da pesquisa em Jornalismo nos Grupos?

ANTÔNIO HOHLFELDT - Poderia ser melhor. Acho que, efetivamente, só o GT de Rádio conseguiu alcançar a dinâmica a que todos almejávamos, mantendo atividades para além do congresso. Mas se você examinar os livros, consultar os anais dos congressos - tanto os nacionais quanto os regionais - e ver a organização de outras entidades, como a dos professores de jornalismo, o de história das mídias e o dos pesquisadores em jor- 
nalismo ou de comunicação corporativa, para citar só algumas, verificará que todas estas entidades nasceram a partir da INTERCOM e tiveram apoio estratégico da INTERCOM, inclusive com cedência da sede de nossa entidade para referência das demais instituições, de modo a permitir-lhes fazer seus registros civis e abrirem suas contas bancárias. Fizemos revisões periódicas dos GTs ou GPs, de maneira a aproximá-los o máximo possível da realidade de pesquisa dos professores brasileiros do campo da comunicação e a maneira pela qual os currículos se apresentam e organizam em nossas universidades. Hoje, temos dezenas de grupos de pesquisa em todo o país, boa parte deles formados a partir da INTERCOM. Especificamente no meu caso, o grupo que integro, junto a colegas do Brasil, Portugal, Cabo Verde e Moçambique, resultou diretamente desta organização dentro da INTERCOM.

EJM - O senhor acredita que há um impacto das pesquisas em Jornalismo na prática jornalística?

ANTÔNIO HOHLFELDT - No Brasil, ainda pouco, por vários motivos, um dos quais a insistência das agências de fomento à pesquisa que valorizam demasiadamente a bibliografia contemporânea, a mais recente possível. De outro lado, a falta de apoio à pesquisa por parte da maior parte de nossas universidades, na medida em que os professores dispõem, verdadeiramente, de pouco tempo a dedicar à pesquisa: as universidades que fazem o contrário são raridades, e com a crise financeira brasileira, vêm diminuindo. Pesquisar exige tempo disponível, paciência, dedicação e concentração: a ideia não cai do céu, ela resulta de consultas continuadas a fontes diversas, leituras múltiplas, e isso não se faz com o controle do relógio, entre uma aula e outra. A multiplicidade de atividades burocráticas, traduzidas em relatórios, por exemplo, é outro fator que atrapalha, mas isso é doença não exclusiva do Brasil, infelizmente.

Eu diria que um desafio importan- te, ao longo da última década, principalmente, tem sido vencido, e aí entra também a importância política da COMPÓS, que reúne os Programas de Pós Graduação em Comunicação: a insistência de que devemos nos ler uns aos outros. Isso mudou muito, melhorou muito, e tem tido repercussão e consequência nas pesquisas realizadas entre nós. Não tem sentido que, para compreendermos o Brasil, nos apoiemos em bibliografia fora do país. Óbvio, ela deve ser sempre pesquisada e conhecida: não somos nem seremos nem devemos ser uma ilha, jamais. Mas precisamos nos olhar a partir de nosso próprio olhar.

\section{EJM - Quais temas o senhor destacaria como relevantes para o futuro da pesquisa em Jornalismo?}

ANTÔNIO HOHLFELDT - Há muitos anos, entre diversos outros pesquisadores, Jesús Martin Barbero chamou a atenção para o fato de que as invenções e conquistas tecnológicas se desenrolam em ritmo muito mais rápido que as pesquisas acadêmicas sobre tais realidades. Este é o desafio constante: estudar, entender, criticar, antecipar as conquistas constantes e relatar resultados de observações. Sem isso, a tecnologia fica sozinha e a gente nem sabe o que ela faz ou como podemos melhor aproveitá-la, democraticamente. Por exemplo: a partir dos acontecimentos de junho de 2013, no Brasil, ou a chamada Primavera Árabe, intensificaram-se os estudos em torno das redes sociais e dos processos democráticos de informação e comunicação, o que é fundamental para a nossa compreensão de tais fenômenos e a derrubada de alguns mitos ou discursos fechados que pretendem pensar as tecnologias sempre como parte do Mal.

Uso muito um texto dos anos 1970, de Hans Magnus Enzensberger, escrito quando ainda não se tinha as redes, chamado "Elementos para uma teoria dos meios de comunicação", em que ele destaca a importância de tecnologias para o estabelecimento de processos democráticos, na medida em que quebram 
a pretendida hegemonia dos emissores. É evidente que as tecnologias não têm vida própria, tudo depende de sua utilização, mas é significativo que um homem de formação marxista, altamente crítico, cuja carreira se desenrola após a hecatombe do nazismo, não seja maniqueísta e reconheça os saltos que estamos a dar no que tange a tais tecnologias. Se aplicarmos o que ele escreve às novas situações contemporâneas, é até divertido observar como ele se torna quase um profeta, ultrapassando até mesmo as observações de McLuhan, muitas vezes (mal) criticado por suas projeções. Acho que temos estudado mal a McLuhan, salvo raras exceções, e desconhecemos, ao menos no Brasil, as reflexões de Enzensberger, o que é lamentável. Há uma tendência de sempre se estudar um determinado fenômeno como se fôssemos os primeiros, esquecendo-nos de que a maioria do que ocorre hoje já aconteceu no passado, apenas com dinâmicas, abrangências e rapidez diversas, evidentemente, muito mais radicais do que o que experimentou antes.

EJM - No seu pós-doutorado, o senhor estudou a história da imprensa em países lusófonos. Há traços em comum entre estas trajetórias e a história da imprensa brasileira?

ANTÔNIO HOHLFELDT - Sim, a minha hipótese e, hoje, minha certeza, é que sim. Primeiro, porque o Brasil também foi uma colônia portuguesa. Segundo, porque, num primeiro momento, quanto ao Brasil colonial, podemos cotejar nossa situação com as políticas portuguesas sobre impressão, quer de livros, quer de jornais. Depois, porque a história do nosso jornalismo começa com a invasão napoleônica, que permitiu com que a Corte portuguesa viesse para o Rio e, a partir daí, tivéssemos a Gazeta do Rio de Janeiro e o Correio Braziliense, impresso em Londres. A partir daí, veremos que a Independência do Brasil, em 1822, modifica radicalmente a política portuguesa quanto às publicações. Em 1836, há um decreto que obriga as administrações coloniais a criarem seus Boletins, o que abre caminho para a chamada imprensa independente.

Neste momento, estou iniciando uma fase de estudos aproximando e comparando o processo espanhol e de suas colônias hispano-americanas do processo luso-brasileiro. Tinha a hipótese, e estou construindo a comprovação disso, de que podemos contar uma única história sobre o jornalismo ibérico e de suas colônias. É fascinante descobrir que os processos paralelos se aproximam e embora alguns lances ou modos de se desenrolar sejam diversos, o grande processo, em si, é exatamente o mesmo. $\mathrm{Na}$ verdade, isso tem certa lógica: o colonialismo era um só, as concepções eram as mesmas, de um determinado tempo, e embora não se falasse em globalização, alguma coisa parecida com isso já vinha ocorrendo desde as descobertas do século XV, na expressão francesa de mundialização - ao invés de globalização.

EJM - Como a reconstituição histórica destes contextos nos auxilia a pensar a formação e consolidação de uma identidade da imprensa nesses países? Há resquícios do período colonial que permanecem?

ANTÔNIO HOHLFELDT - Escrevi há tempos o texto de uma conferência que fiz na Universidade do Minho, em Braga, mostrando a importância de se conhecer o passado para se entender o presente. Isso não é passadismo, saudosismo, melancolia ou algo assim. Tomemos um simples exemplo. Hoje em dia fala-se na modificação do papel do jornalista por causa das tecnologias. Ele não seria mais fonte de informação, apenas editaria e selecionaria informações. E o que ocorria, por exemplo, no século XIX? Tomemos o editor da Gazeta do Rio, o que ele fazia? Lia diversos jornais, selecionava o que entendia ser interessante, copiava, complementava, editava e publicava. Saía de sua redação? Não, a informação chegava até ele, tal como hoje ocorre graças às redes sociais. Isso é bom ou é ruim? Pode ser bom e/ou ruim, depende do que se faz com isso. Por exemplo, o 
jornalismo investigativo depende muito de bases de dados. Mas certamente o jornalista precisará fazer contatos, tal como ocorreu nos episódios do Watergate. Ora, no século XIX era isso que ocorria. Um jornal lia outro jornal, que lera um terceiro e um quarto, e assim por diante. Também havia redes de informação, claro, sem a amplitude, a rapidez e a abrangência do que experimentamos hoje. Mas o que vivemos hoje não é radicalmente novo. É apenas uma ampliação do que já existiu antes.

Em meu tempo de redação do Correio do Povo, na edição do suplemento cultural Caderno de Sábado, eu viajava muito para assistir exposições, conferências e concertos e escrevi loucamente para todos os escritores que conhecia, para que eles enviassem textos para o jornal. Isso já era uma rede social, mesmo que sem as tecnologias de hoje. Quando o jornalista e escritor João Antonio faleceu, no seu acervo encontraram uma cadernetinha de endereços. Na verdade, duas: aquela que era mais efetiva e constante, dela constando nomes para quem ele envia permanentemente seus textos, dando-lhes primazia, e outra, mais distante. $\mathrm{E}$ que processo era este: máquina escrever Lettera 88 , da Olivetti, papel carbono e laudas de jornal. A cada vez se podia fazer umas cinco cópias, que era o que o carbono permitia. Depois, envelopava-se, selava-se e se despachava a carta para o endereço pretendido. Dez dias depois lá chegava a carta, com o artigo, o poema, um conto inédito. $\mathrm{E}$ era publicado. Hoje podemos fazer tudo isso em segundos, distribuindo a muito mais gente, indo muito mais longe, etc. Mas o princípio, em si, é o mesmo. E, sim, o jornalista continua sendo o gatekeeper, mais que qualquer outra função. E o leitor dependerá da capacidade crítica do jornalista para discernir, compreender e antecipar fatos, para ter uma boa informação.

Um trabalho de TCC de um aluno meu, há tempos, comprovou isso: o que informaria mais, um site online de O Estado de São Paulo, diretamente vinculado à bolsa de valores, que acompanha 24 horas por dia a oscilação dos preços das ações, ou a publicação de um jornal como a antiga Gazeta Mercantil ou o atual Valor Econômico, que informa e interpreta as informações? Aliás, Luiz Beltrão, em "Introdução à filosofia do jornalismo", obra pioneira lá dos anos 60 , já chamava a atenção para isso. $O$ jornalismo não só relata, ele, sobretudo, interpreta e, com isso, antecipa acontecimentos. Por isso defendo a necessidade de um curso de jornalismo. Como preconizou Joseph Pulitzer, quando propôs a criação do primeiro curso de jornalismo nos Estados Unidos, a função do jornalista é eminentemente social exatamente por este tipo de atividade. Para isso, o jornalista não se deve curvar à opinião pública - ele até pode interferir nela, mas não deve depender dela. Por isso, o jornalista precisa ter formação ampla, espírito crítico, imensa curiosidade e dose fundamental de desconfiança. Precisamos ser crentes céticos, sempre, e fazer aquela pergunta que não quer calar, que não querem que seja feita. Este seria o principal compromisso, eu diria, de um curso de jornalismo: desenvolver o espírito crítico do aluno, futuro profissional jornalista. 